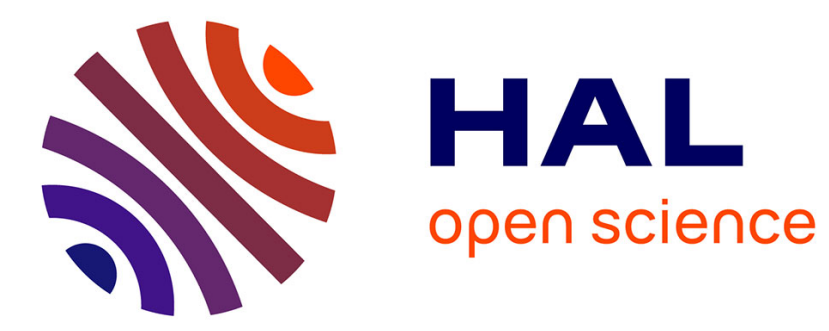

\title{
On the Use of Cognitive Maps to Identify Meaning Variance
}

\author{
Pierre-Emmanuel Arduin
}

\section{To cite this version:}

Pierre-Emmanuel Arduin. On the Use of Cognitive Maps to Identify Meaning Variance. Lecture Notes in Business Information Processing, 2014, 180, pp.73-80. hal-01061008

\section{HAL Id: hal-01061008 \\ https://hal.science/hal-01061008}

Submitted on 4 Sep 2014

HAL is a multi-disciplinary open access archive for the deposit and dissemination of scientific research documents, whether they are published or not. The documents may come from teaching and research institutions in France or abroad, or from public or private research centers.
L'archive ouverte pluridisciplinaire HAL, est destinée au dépôt et à la diffusion de documents scientifiques de niveau recherche, publiés ou non, émanant des établissements d'enseignement et de recherche français ou étrangers, des laboratoires publics ou privés. 


\title{
On the Use of Cognitive Maps to Identify Meaning Variance
}

\author{
Pierre-Emmanuel Arduin \\ Heudiasyc UMR CNRS 7253, University of Technology of Compiègne \\ Rue Roger Couttolenc, CS 60319, 60203 Compiègne Cedex, France \\ pierre-emmanuel.arduin@utc.fr \\ http://www.hds.utc.fr/ arduinpi
}

\begin{abstract}
Cognitive science, as well as psychology, considers that individuals use internal representations of the external reality in order to interact with the world. These representations are called mental models and are considered as a cognitive structure at the basis of reasoning, decision making, and behavior.

This paper relies on a fieldwork realized as closely as possible from the respondents. We propose an approach based on graph theory in order to study the meanings given by several people to the same concept, and to identify those who give it the same meaning.

The use of tools from graph theory combined with the study of cognitive maps leaded us to highlight the importance of interaction notably within group decision making. This idea, as well as the limits of our approach, are discussed at the end of this paper.
\end{abstract}

Key words: cognitive map, mental model, graph theory, interaction, group decision making.

\section{Introduction}

Mental models are "personal, internal representations of external reality that people use to interact with the world around them" for Jones et al. in [10]. These representations are abstractions of the reality relying notably for an individual on his/her personal experiences, perceptions and understanding of the world that surrounds him/her.

These representations may vary from one person to another, as well as the meanings they give to the same concept. For Daft and Weick, "Interpretation gives meaning to data, but it occurs before organizational learning and action." ([5], p. 286), that it the reason why we consider that identifying meaning variance could be useful for group decision making or negotiation. If authors as Hall et al. in [9] and Morgan in [18] focus on cognitive mapping as a way to improve management and to study communication breakdown risks, others as Quinn in [20] and Langan-Fox et al. in [15] consider cognitive mapping as a way to elaborate a "shared or team mental model" ([15], p. 242). For Eden and Ackermann in [7], cognitive maps can be used for issue structuring in the context of a group decision support system. 
In this article, we propose an approach in order to identify people who give the same meaning to the same concept through the use of cognitive maps and their analysis with tools of graph theory. The efficiency of the proposed approach relies notably on the fieldwork with the respondents: the meanings they give to the same concept have to be understood. After introducing background theories in the area of cognitive mapping, we present tools of graph theory in order to study cognitive maps. Our own approach is then explained and discussed, from the interviewing of the respondents to the identification of meaning variance through the use of their cognitive maps.

\section{Background Theory and Assumptions}

This study relies on the assumption that two individuals give the same meaning (respectively different meanings) to the same concept if and only if their cognitive maps related to this concept are practically similar (respectively different). Section 2.2 refines this idea of "quasi-similarity".

Mental models and their elicitation with cognitive maps are introduced in the first part of this section. Tools of graph theory which can be used to study cognitive maps are then presented in the second part of this section.

\subsection{Mental models and their elicitation through cognitive maps}

In 1943, Craik drew a parallel between machines functioning and human brain in [4]. This parallel leaded to mental models, which are functional representations of the reality: we use them to interact with the world. They are functional in the sense that they are simplified and incomplete.

Klayman and Ha, with the theory of "confirmation bias", suggest in [14] that individuals seek information adapted to their actual understanding of the world. Indeed for Collins and Gentner in [3], when you explain a domain with which you are unfamiliar, you try to instantiate it on a familiar domain, that you think as being similar. You can for example use water flow to explain electrical current.

Cognitive maps are knowledge structures representing for an individual his/her assumptions and beliefs on the world for Kearney and Kaplan in [13]. These assumptions and beliefs provide himself/herself a framework to interpret new information and to elaborate decisions regarding on new situations ([11] and [12]). Eden sees cognitive maps as "model of thinking" ([6], p. 261). Jones et al. highlight in [10] how cognitive mapping allows studying understanding similarities and differences between several people. Most of the procedures used to elicit mental models consider that they can be represented as a network of concepts and relations and rely on direct or indirect elicitation:

Direct Elicitation The respondent is here asked to realize a representation of his/her mental model by using drawings, words, and symbols. In [13], the authors introduce a method where the participants must identify the concepts that they consider as important for a given domain, and organize them visually / spatially in a way that represents their understanding of the given domain. 
Indirect Elicitation For Carley and Palmquist in [2], the representation of a mental model can be extracted from written documents or oral propositions.

Mental models elicitation has to focus not only on the concepts that are considered as important, but also on the way they are organized from a cognitive point of view and on their interactions. Cognitive mapping is the process for someone of realizing a cognitive map of his/her mental model related to a domain. It leads to understand how people understand a system. Group decision making and negotiation could be improved if individuals with different points of view are stimulated to work together. A shared understanding has to be identified and supported between the different stakeholders for Jones et al. in [10]. For Weick, a kind of "convergence" can be obtained across managers ([21], p. 80). Decision making processes concern simultaneously individuals, groups, and societies. That is the reason why identifying meaning variance, i.e. differences of understanding, has to be considered as a source of improvements for negotiation and group decision making.

\subsection{Analyzing cognitive maps with tools of graph theory}

Ozesmi and Ozesmi use in [19] the elicitation of mental models by asking respondents to define important variables for a given system. These variables are then written on cards and the respondents have to organize them in a way that reflects their understanding of the system. Ozesmi and Ozesmi propose to use graph theory tools in order to explore the complexity of the constructed networks. The density is for example a way to study cognitive maps, by counting the nodes $(N)$ and the connections $(C)$, the density $(D)$ can be determined as follows:

$$
D=\frac{C}{N^{2}}
$$

more the density is high, more the number of relations between the concepts in the cognitive map is high. The hierarchical index from Mac Donald, noted $h$ and introduced in [17], can also be envisaged:

$$
h=\frac{12}{(N-1) N(N+1)} \sum_{v}\left[\frac{d^{-}(v)-\sum d^{-}(v)}{N}\right]^{2}
$$

where $N$ is the total number of nodes and $d^{-}(v)$ the outdegree of the node $v$. The value of this index is 0 when the system is democratic and 1 when it is hierarchical. The interested reader can have a look at [19] or [16] where the authors present these measures and others. They are notably interested in the most mentioned nodes and in the most central nodes. The firsts are those which are mentioned by the most important number of respondents, whereas the seconds are those which have, for a given respondent, the higher degree in his/her cognitive map. Our approach focuses on these two last measures, which allow rapid experimentations. In the future, they will be compared with others measures in order to justify the relevance of this choice. 


\section{Our Approach to Identify Meaning Variance}

The study presented in this section has been realized with the participation and the agreement of five Computer Science students and five Management Science students at Paris-Dauphine University in 2013.

The first part of this section presents the way of conducting the interviews. The construction of the results is then explained in the second part of this section. Finally these results are discussed in the last part of this section. Every concept given by the students has been translated into English.

\subsection{Conducting the interviews}

First of all when you intend to conduct cognitive mapping interviews, you have to realize your own cognitive map of the studied concept. This precaution may prevent reactions you may have during the interviews and that would influence the ongoing cognitive mapping. "Information System" is the studied concept in this work.

The number of interviews has also to be considered. We limited our study to ten interviews not only for practical reasons, but also according to Ozesmi and Ozesmi that noticed in [19] how the number of new concepts can stagnate depending on the number of interviews (see figure 1). For Carley and Palmquist in [2], this stagnation may result from a limited vocabulary for a given subject. Glaser and Strauss in [8] consider notably that a researcher "trying to reach saturation [...] maximizes differences in his groups in order to maximize the varieties of data bearing on the category" (p. 62).

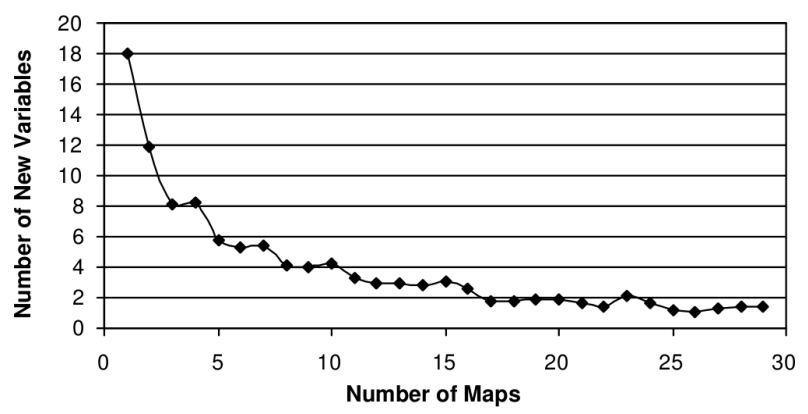

Fig. 1. The number of new concepts depending on the number of interviews (source: Ozesmi and Ozesmi in [19])

The interviews have all been realized individually and the relation between the researcher and the respondent has clearly been explained: this is not an exam, there is no evaluation. The average duration of an interview was 7'14". Post-it notes and a pen were given to the respondent and we began asking: "Imagine that you have to explain what an "Information System" is to someone who absolutely does not know what it is. What concepts or ideas do you need?". 
The respondent was invited to write these concepts on as many post-it notes as necessary. The average time between the end of the question and the beginning of an answer was 10,29 seconds. Even when he/she thought he/she had finished, we asked our question again in order to ensure that no concept was forgotten. Then a large piece of paper was given to the respondent, who was invited to organize his/her post-it notes. New concepts could be added at every moment, and at the end we asked to the respondent if the production he/she realized corresponds to the representation for him/her of an "Information System", i.e. if this production corresponds to the meaning he/she gives to this concept.

\subsection{Constructing the results from the interviews}

The figure 2 represents the graph associated to the cognitive map generated by the first respondent for the concept of "Information System". The links between nodes are not necessarily causal as it may be the case in cognitive maps. The most mentioned nodes and those which are the most central are now going to be studied.

The firsts are determined by counting the number of occurrences of every node, so that within our sample of respondents "Data", "Human Resources" and "Information" are the most mentioned nodes (these results are presented more precisely in [1]). The seconds are determined by regarding every cognitive map as an undirected graph. Post-it notes become nodes and their position as well as their relationships become edges. So that in the case of the first cognitive map, whose associated graph is presented figure 2, the most central nodes are "Information" and "Human Resources": these nodes are the most connected to the rest of the graph. Table 1 represents for our sample of respondents the most central nodes per respondent, regarding to the most mentioned nodes. From this table the figure 3 can be generated and highlights the respondents which have common central nodes regarding to the most mentioned nodes: the meaning they gave to the concept of "Information System" seems to be closer for them (in green) than for the others (in white). The reader may have noticed several respondents who have no central nodes regarding to the most mentioned nodes (respondents 2, 3, and 9). Indeed their most central nodes are not related to the most mentioned nodes. We say that the meaning they gave to the concept of "Information System" is unusual for the considered group.

\subsection{Discussing the results}

The major restriction of our approach is that it is reductive because it focuses only on the most mentioned and on the most central nodes. This restriction, induced by Ozesmi and Ozesmi in [19] constitutes nevertheless a strength of our approach: it is necessary in order to treat cognitive maps, which can rapidly lead to complex graphs. According to our experimentations, this restriction, even if it reduces cognitive maps semantic only to the most mentioned and the most central nodes, strongly accelerates the way of conducing that kind 


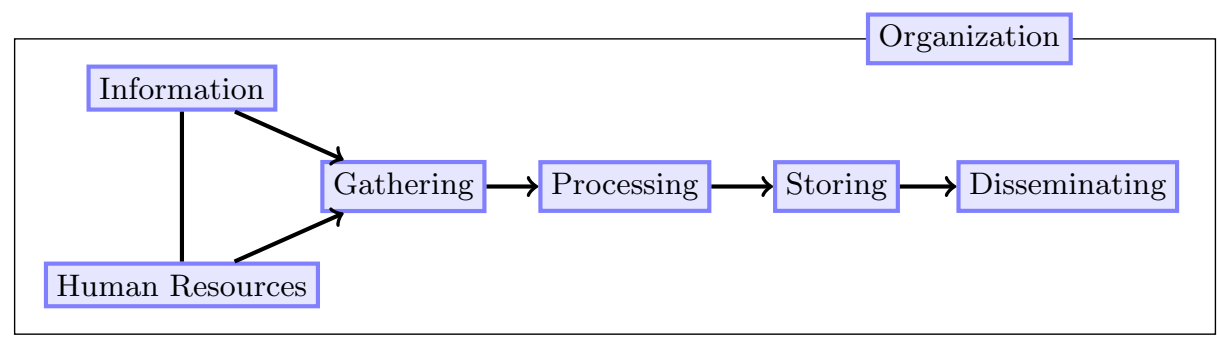

Fig. 2. The graph associated to the cognitive map generated by the first respondent for the concept of "Information System"

\begin{tabular}{c||c|c|c} 
& Data & Human resources & Information \\
\hline \hline Respondent 1 & & Human resources & Information \\
\hline Respondent 2 & & & \\
\hline Respondent 3 & & & \\
\hline Respondent 4 & & Human & \\
\hline Respondent 5 & Database & & Information \\
\hline Respondent 6 & Data & & \\
\hline Respondent 7 & & User & \\
\hline Respondent 8 & Data Structure & & \\
\hline Respondent 9 & & & Dissemination of Information
\end{tabular}

Table 1. The most central nodes per respondent (lines), regarding to the most mentioned nodes (rows)

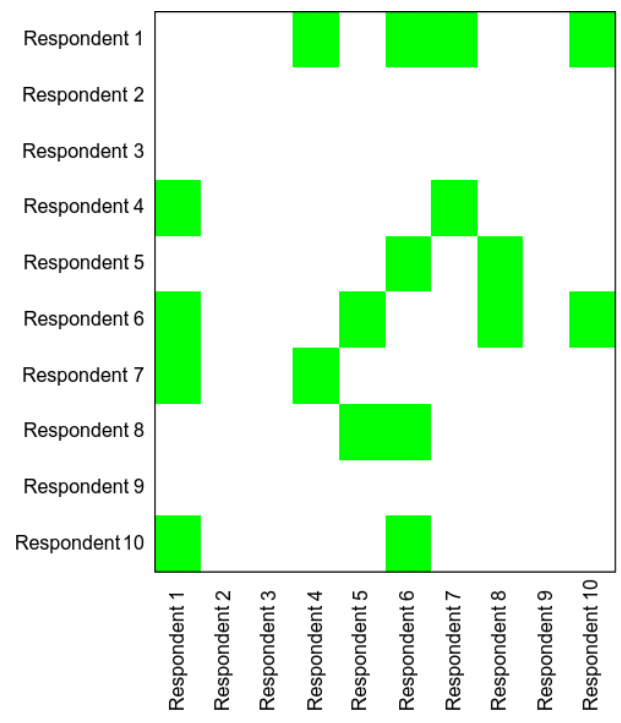

Fig. 3. Respondents whose central nodes are common regarding to the most mentioned nodes, the meaning they gave to the concept of "Information System" seems to be close 
of investigation. The results can easily be processed by concept-mapping and mind-mapping software for example.

The reader may have noticed in the figure 3 that the respondents 1 and 6 are those who central nodes are common to the greater number of persons regarding to the most mentioned nodes. Table 1 shows how these respondents are those who have several central nodes. This observation leaded us to conclude that the meaning they gave to the concept of "Information System" covers several meanings given by the others respondents. We are now trying to establish a connection between the cognitive maps, i.e. the most central nodes for a respondent, and his/her academical background, i.e. if he/she is a Computer Science student or a Management Science student.

\section{Conclusions and future works}

In this paper we presented an approach in order to identify meaning variance between the members of a group by analyzing their cognitive maps through the use of graph theory tools. We began introducing background theories in the area of mental models and cognitive mapping. We presented then tools of graph theory which can be used to study cognitive maps. We finally explained and discussed our approach from the interviewing of the respondents to the identification of meaning variance through the use of their cognitive maps.

Individually and during face-to-face interviews, our approach has been thought as closely as possible from the respondents. A concept is given and the respondents are then asked to represent their understandings of this concept. These representations are analyzed with tools of graph theory in order to highlight the respondents who gave a similar meaning to the given concept. It is crucial to give to the respondents the time to realize their representations. The atmosphere must be relaxed and the respondents have to feel confident.

Nevertheless our approach is reductive in the data considered. Relying on Ozesmi and Ozesmi [19] notably, we proposed to focus only on the most mentioned nodes and on the most central nodes in order to analyze respondents' cognitive maps. This weakness is otherwise a strength of our approach: it makes feasible an analysis expensive to realize when the cognitive map as a whole is considered.

The conducted interviews lead us to consider not only the concepts identified by the respondents, but also their meanings. Only with ten students and during an academical case study, we observed so much that people can give different meanings to the same concept. We are now focusing on interactions during group decision making in order to observe, to identify, and to manage meaning variance through the use of cognitive maps.

Acknowledgments This paper has been prepared during the $\mathrm{PhD}$ of the author under the direction of Camille Rosenthal-Sabroux and Michel Grundstein. He is grateful to both of them for their support and advice. He would also like to thank the students who have accepted to take the time to be interviewed. 


\section{References}

1. P-E. Arduin. Vers une métrique de la commensurabilité des schémas d'interprétation (English title: Towards a metric of the commensurability of interpretative frameworks). PhD thesis, Paris-Dauphine University, 2013.

2. K. Carley and M. Palmquist. Extracting, representing, and analyzing mental models. Social Forces, 70(3):601-636, 1992.

3. A. Collins and D. Gentner. How people construct mental models. In D. Holland and N. Quinn, editors, Cultural Models in Language and Thought, chapter 10, pages 243-265. Cambridge University Press, 1987.

4. K.J.W. Craik. The Nature of Explanation. Cambridge University Press, 1943.

5. R.L. Daft and K.E. Weick. Toward a model of organizations as interpretation systems. The Academy of Management Review, 9(2):284-295, 1984.

6. C. Eden. On the nature of cognitive maps. Journal of Management Studies, 29(3):261-265, 1992.

7. C. Eden and F. Ackermann. Group decision and negotiation in strategy making. Group Decision and Negotiation, 10(2):119-140, 2001.

8. B.G. Glaser and A.L. Strauss. The Discovery of Grounded Theory: Strategies for Qualitative Research. Chicago, Aldine Publishing Company, 1967.

9. R. I. Hall, P. W. Aitchison, and W. L. Kocay. Causal policy maps of managers: Formal methods for elicitation and analysis. System Dynamics Review, 10(4):337360, 1994.

10. N.A. Jones, H. Ross, T. Lynam, P. Perez, and A. Leitch. Mental models: An interdisciplinary synthesis of theory and methods. Ecology and Society, 16(1), 2011.

11. S. Kaplan and R. Kaplan. Environments for people, chapter Attention and fascination: The search for cognitive clarity. MI: Ulrich's, 1982.

12. S. Kaplan and R. Kaplan. Cognition and environment: Functioning in an uncertain world. MI: Ulrich's, 1989.

13. A. R. Kearney and S. Kaplan. Toward a methodology for the measurement of the knowledge structures of ordinary people: The conceptual content cognitive map (3CM). Environment and Behavior, 29(5):579-617, 1997.

14. J. Klayman and Ha Y.-W. Hypothesis testing in rule discovery: Strategy, structure, and content. Journal of Experimental Psychology, 5:596-604, 1989.

15. J. Langan-Fox, S. Code, and K. Langfield-Smith. Team mental models: Techniques, methods, and analytic approaches. Human Factors, 42(2):242-271, 2000.

16. K. Langfield-Smith and A. Wirth. Measuring differences between cognitive maps. Journal of the Operational Research Society, 43:1135-1150, 1992.

17. N. MacDonald. Trees and Networks in Biological Models. John Wiley and Sons, 1983.

18. M. G. Morgan. Risk Communication: A Mental Models Approach. Cambridge University Press, 2002.

19. U. Ozesmi and S. L. Ozesmi. Ecological models based on peoples knowledge: a multi-step fuzzy cognitive mapping approach. Ecological Modelling, 176:43-64, 2004.

20. N. Quinn. Finding culture in talk: a collection of methods, chapter How to reconstruct schemas people share, pages 33-81. Palgrave Miller, 2005.

21. K.E. Weick. Sensemaking in Organizations. Foundations for Organizational Science. SAGE Publications, 1995. 